\title{
Dual case report of hemoglobin sc disease in pregnancy
}

\begin{abstract}
Background: Hemoglobin SC disease (HbSC) is second only to sickle cell anemia (SCA) as the most common hemoglobinopathy. Pregnant women with SCA are known to be at high risk of obstetrical complications and perinatal mortality as well as sickle related complications. The aim of this study is to review the morbidity and mortality associated with pregnancies complicated by haemoglobinopathies.
\end{abstract}

Case(s): We describe two cases of HbSC disease complicating pregnancy with episodes painful crises and anemia. Both patients were managed with hydration, blood transfusions and analgesia. One of the pregnancies was complicated by other co-morbidities cholestasis of pregnancy, preeclampsia and postpartum hemorrhage.

Conclusion: Painful crises, preterm delivery and preeclampsia are frequently complicate pregnancy affected by SCD. Although HbSC genotype typically presents a more benign clinical evolution than HbSS, both may present with complications of similar severity. Parturients with SCD regardless of their genotype should be managed by a multidisciplinary approach and carefully monitored to limit maternal and fetal complications.

Keywords: Acute chest syndrome (ACS), Acute Joint crisis, HbSC, Hemoglobin SC disease, Hyperviscosity, Phlebotomy, Pregnancy, SCD, Sickle cell anemia (SCA), Sickle cell anemia, Sickle cell crisis, Sickle Cell Disease (SCD), Sickle cell pain crisis, Sickle cell painful joint crisis, Sickling disorder, Vaso-occlusive crisis (VOC)
Volume 4 Issue 3 - 2016

\author{
Shadi Rezai,' Gina Cavallo, ${ }^{2}$ Sri \\ Gottimukkala,' Ray Mercado,' Cassandra E \\ Henderson' \\ 'Department of Obstetrics and Gynecology, Lincoln Medical \\ and Mental Health Center, USA \\ ${ }^{2}$ St. George's University, West Indies
}

\begin{abstract}
Correspondence: Cassandra E Henderson, CDE, Director of Maternal Fetal Medicine, Lincoln Medical and Mental Health Center, 234 East 149th Street, Bronx, NY, 1045I, USA,
\end{abstract} Email Cassandra.henderson@nychhc.org

Received: December 23, 2015 | Published: February 19, 2016

\section{Introduction}

Heterozygous hemoglobin sickle cell disease (HbSC) is the second most frequent hemoglobinopathy behind SCA. ${ }^{1}$ Individuals with $\mathrm{HbSC}$ are heterozygous having received the $\beta \mathrm{C}-$ gene for hemoglobin $\mathrm{C}$ from one parent and the $\beta \mathrm{S}-$ gene for hemoglobin $\mathrm{S}$ from the other parent. ${ }^{2,3} \mathrm{HbSC}$ red cells contain equal levels of $\mathrm{HbS}$ and $\mathrm{HbC}$. The blood smears of individuals with $\mathrm{HbSC}$ contain primarily Target cells with few sickle cells. ${ }^{4}$

Although $\mathrm{HbS}$ and $\mathrm{HbC}$ (trait) have little clinical consequence, HbSC is accompanied by significant clinical abnormalities. ${ }^{2,5}$ While sickled red blood cells are a phenotype of HbSS, sickling is less commonly associated with $\mathrm{HbSC}$ in the presence of a normal hemoglobin allele as it does not polymerize as readily as HbSS. It is a paradox that $\mathrm{HbSC}$ exhibit a moderately severe phenotype in spite of being a mixture of $\mathrm{HbS}$ trait and $\mathrm{HbC}$ trait, neither of which alone has significant pathology. The combination of SC hemoglobin alleles results in a serious disease due to the dehydrating properties of hemoglobin $\mathrm{C}$ on the $\mathrm{SC}$ red cell thereby creating a favorable environment for the pathogenic properties of $\mathrm{HbS}^{6}$

While survival appears to be higher in $\mathrm{HbSC}$ than HbSS there are still unpredictable life-threatening events associated with $\mathrm{HbSC}^{7}$ Occurrence of vaso-occlusive events precipitate acute painful episodes. ${ }^{89}$ Common precipitants of sickle cell crisis are infection, dehydration, cold temperatures, altitude, pregnancy, and low fetal hemoglobin. ${ }^{10}$ The usual presentation is pain that tends to be identified by the patient as typical of a crisis. The most common areas for pain are the lower back, chest, femoral shaft and hip joints, ribs, knees, abdomen, and head. At times, it can be difficult to differentiate an acute abdomen that requires surgery from a painful crisis that presents as abdominal pain. This is made more difficult in the presence of a gravid uterus. It is imperative that all other possible causes of pain be ruled out before establishing the diagnosis of a sickle cell crisis. ${ }^{11}$

It is known that SCD complicates pregnancy leading to maternal and fetal morbidity and mortality. While HbSC disease is clinically more benign it may present with manifestations as severe as HbSS disease. Complications including painful crises, preterm delivery, preeclampsia, post-partum hemorrhage and anemia have been well documented in the literature for both $\mathrm{HbSS}$ and $\mathrm{HbSC}$ disease. While these complications tend to occur less frequently in $\mathrm{HbSC}$ disease they have not been shown to be statistically significant between the two genotypes of SCD. Women with HbSC may experience complications as severe as those associated with the HbSS genotype during pregnancy and should be monitored carefully. ${ }^{12}$

\section{Case(s)}

The first patient is a 22-year-old, female from Guinea (West Africa), G1P0 with HbSC disease. She received prenatal care in our obstetrics high-risk clinic that was co-managed with hematology. The pregnancy was complicated by the underlying hemoglobinopathy. During the antenatal period there multiple admissions for complaints of painful crisis in her shoulders, hips and back. Management included intravenous hydration, oxygenation and analgesics. On her second admission the patient's chief complaint was bilateral hip pain with increased severity on the left side. Radiologic imaging did not demonstrate a vascular necrosis of femoral head. Her pain was refractory to Tylenol with codeine and Dilaudid was used for analgesia. An uncomplicated normal spontaneous vaginal delivery (NSVD) of a viable 2995-gram male occurred at 402/7 weeks. Apgar scores of 9 and 9 were recorded at 1 and 5 minutes, respectively. During the postpartum period, the patient received physical and rehabilitation therapy. 


\section{Laboratory values:}

CBC:
a) HB: $9.9(12.0-16.0 \mathrm{~g} / \mathrm{dL})$
b) Hct: $30.3(37-47 \%)$
c) MCV: $96.4(80.4-95.9 \mathrm{fL})$
d) RDW: $17.9(12-15 \%)$
e) Plt: 376 (150-400 109/L)
f) WBC: $15.9(4.8-10.8$ 109/L)
g) PMN: $11.6(2.1-7.6)$

h) Reticulocyte: $5.8(0.50-2.0 \%)$

\section{Liver Function Tests (LFTs)}
i. AST: $52(11-39 \mathrm{U} / \mathrm{L})$
ii. ALT: 38 (11-35 U/L)
iii. ALP: 151 (25-100 U/L)

(Previous value AST 37, ALT 36 and ALP 103U/L were recorded as normal on September 30, 2014)

iv. Total bilirubin: $1.2 \mathrm{mg} / \mathrm{dL}(0.2-1.3 \mathrm{mg} / \mathrm{dL})$

v. Direct bilirubin elevated at $0.6 \mathrm{mg} / \mathrm{dL}(0.0-0.2 \mathrm{mg} / \mathrm{dL})$

vi. Total protein: $7.7(6.3-8.2 \mathrm{~g} / \mathrm{dL})$

vii. Albumin: $3.5(3.7-5.1 \mathrm{~g} / \mathrm{dL})$

viii. LDH: 325 (110-225)

Hemoglobin pattern: $\mathrm{SC}, \mathrm{HbF} 1 \%$, Hb A2 3.8\% (Normal 2-3\%), $\mathrm{Hb} \mathrm{S} 47.7 \%$ (Normal 0-0.001\%), Hb C $47.5 \%$ (Normal 0-0.001\%)confirmed by Alkaline and Acid Hemoglobin electrophoresis. The second patient is a 35-year-old female from Ghana (West Africa) G2P1 with HbSC disease. Her pregnancy was complicated by the underlying hemoglobinopathy, short cervix and cholestasis of pregnancy. Her pregnancy was co-managed by the obstetrics high risk clinic and hematology clinic. She presented at 39 2/7 weeks for generalized joint pain for 3 days. She reported a history of vasoocclusive crises and sickle cell induced retinopathy but denies any recent events prior to admission. Admission treatment plan was management of pain associated with sickle crisis and induction of labor (IOL). Labor management included Cytotec, IV hydration, pain management, folic acid and continuous oxygen.

At 39 2/7 weeks of gestation a viable 3000-gram female baby was born via NSVD. Apgar scores of 9 and 9 were recorded at 1 and 5 minutes, respectively. The delivery was uncomplicated but the postpartum period was complicated by preeclampsia and postpartum hemorrhage with estimated blood loss of $700 \mathrm{cc}$. She received 3units of packed red blood cells and was transferred to the medicine unit for further monitoring.

\section{Laboratory values:}

CBC:
a. HB: $9.9(12.0-16.0 \mathrm{~g} / \mathrm{dL})$
b. Het: $29.3(37-47 \%)$
c. MCV: 95.8 (80.4- $95.9 \mathrm{fL})$
d. RDW: 13.7 (12-15\%)

e. Plt: 311 (150-400 109/L)

f. WBC: 25.4 (4.8-10.8 109/L)

g. PMN: 23.5 (2.1-7.6)

h. Reticulocyte: $6.68(0.50-2.0 \%)$

Liver Function Tests (LFTs):

a) AST: 195 (11-39 U/L)

b) ALT: 116 (11-35 U/L)

c) ALP: $227(25-100 \mathrm{U} / \mathrm{L})$

(Previous value AST 56, ALT 49 and ALP 168U/L were recorded as mildly elevated on November 14, 2014)

d) Total bilirubin: $1.9 \mathrm{mg} / \mathrm{dL}(0.2-1.3 \mathrm{mg} / \mathrm{dL})$

e) Direct bilirubin elevated at $0.8 \mathrm{mg} / \mathrm{dL}(0.0-0.2 \mathrm{mg} / \mathrm{dL})$

f) Total protein: $6.7(6.3-8.2 \mathrm{~g} / \mathrm{dL})$

g) Albumin: $2.5(3.7-5.1 \mathrm{~g} / \mathrm{dL})$

h) LDH: 454 (110-225)

Hemoglobin pattern: SC, $\mathrm{HbF} 0.7 \%$, Hb A2 4.1\% (Normal 2-3\%), $\mathrm{Hb}$ S $48.1 \%$ (Normal 0-0.001\%), Hb C $47.1 \%$ (Normal 0-0.001\%) confirmed by Alkaline and Acid Hemoglobin electrophoresis.

\section{Discussion}

HbSC disease causes symptoms similar to those of homozygous (SS) sickle cell anemia (SCA) such as vaso-occlusive episodes and organ damage. ${ }^{2}$ with milder severity and less frequency. ${ }^{2,6,13}$ Although $\mathrm{HbSC}$ has been considered a benign form of SCA in the general population, the incidence of retinitis proliferans, osteonecrosis, ${ }^{6,14}$ and acute chest syndrome ${ }^{6}$ is comparable. In addition, gross hematuria, retinal hemorrhages, and aseptic necrosis of the femoral head are more common in HbSC disease. ${ }^{4}$ The life-long hemolytic anemia associated with $\mathrm{HbSC}$ disease is milder than the anemia in SS. ${ }^{2}$ and some patients even have normal hemoglobin levels. This is evidenced by the red cell life-span being approximately two-fold higher in HbSC than in SCA patients (28.9 days vs 15 days, respectively). ${ }^{15,16}$

One study compared the outcome of painful crisis during pregnancy between women with $\mathrm{HbSS}$ and $\mathrm{HbSC}$ disease and found that $34 \%$ of SC patients and $50 \%$ of SS patients had at least one pain crisis during pregnancy. Preterm delivery occurred in $20 \%$ of patient who had HbSC disease versus $45 \%$ of patient with SS disease. The rate of preeclampsia was $8.7 \%$ and $20 \%$, respectively. ${ }^{17}$

Another study showed pregnant women with hemoglobin SC disease had a significantly increased risk of antepartum hospitalization, intrauterine growth restriction and post-partum infection compared to those without the disease. During pregnancy $40-60 \%$ of patients with $\mathrm{HbSC}$ disease presented with symptoms as if they had HbSS disease. They frequently experienced rapid and severe anemic crisis and had a higher tendency to experience bone marrow necrosis. ${ }^{18}$

A recent cohort study in the UK compared the maternal and fetal outcomes of SCD in pregnancy specifically focusing on the outcomes of the two most common genotypes, HbSS and HbSC. ${ }^{19}$ The mean $\mathrm{Hb}$ was lower in the HbSS group when compared to the HbSC group. Women with $\mathrm{HbSS}$ were significantly more likely to receive a transfusion during pregnancy than women with $\mathrm{HbSC}$. Painful crises were also more common in women with HbSS than in women with 
$\mathrm{HbSC}$ with $76.5 \%$ of women with $\mathrm{HbSS}$ and $27.3 \%$ of women with $\mathrm{HbSC}$ experiencing this complication $(\mathrm{p}<0.001)$. Severe or extremely severe crises requiring hospital attendance or admission occurred in $17.6 \%$ of women with $\mathrm{HbSS}$ and $9.1 \%$ of women with $\mathrm{HbSC}(\mathrm{p}=0.23)$. Acute chest syndrome was seen in both $\mathrm{HbSS}$ and $\mathrm{HbSC}, 9.8 \%$ and $4.6 \%(\mathrm{p}=0.3)$, respectively. There were no significant differences in the incidence of hypertensive disease between women with HbSS and HbSC. Renal insufficiency and venous thromboembolism were also similarly distributed in the HbSS and HbSC groups. Delivery was more likely to take place at term in pregnancies complicated by $\mathrm{HbSC}$ when compare to HbSS, $74.6 \%$ vs $35.4 \%$ ( $<<0.001$ ). However, when compared to pregnancies not affected by hemoglobinopathy, delivery at $<34$ weeks was increased in both $\mathrm{HbSS}$ and $\mathrm{HbSC}$ women. Post partum hemorrhage was more likely in women with $\mathrm{HbSC}$ than $\mathrm{HbSS}$, as was seen in one of our patients. As evidenced by the study cited above, pregnancy in SCD is a high risk time and is associated with an increased incidence of sickle and non-sickle related complications. The most common antenatal complication of SCD was acutepain, which was reported in $21 \%$ of affected pregnancies. Outside of pregnancy, $\mathrm{HbSC}$ has a less severe phenotype than $\mathrm{HbSS}$ but there is a spectrum of severity and those with $\mathrm{HbSC}$ can have frequent severe pain episodes and manifest all of the chronic complications of SCD. ${ }^{20}$

A study from Ghana of 112 women with $\mathrm{HbSC}$ showed no significant difference in pain between the two groups. The prevalence of pregnancy related complications was lower in the HbSC group, the only significant differences from HbSS were in the rates of pregnancy induced hypertension and premature rupture of membranes, which were higher in the HbSS group when compared to HbSC. Interestingly, $\mathrm{HbSC}$ women had an increased risk of intra-uterine fetal death but a decreased risk of low birth weight babies compared to both HbSS and the control HbAA group. No increase in premature delivery was seen in either the HbSS or HbSC women. The authors concluded that HbSC pregnancies were associated with fewer complications. ${ }^{20}$

Our review suggests that neither genotype complicating should be considered benign. According, most studies have found HbSS adversely affects pregnancies, most commonly causing painful crisis. But, gravidas with $\mathrm{HbSC}$ also experience similar complications that are unpredictable in nature. Although both of our patients had the $\mathrm{HbSC}$ genotype, they presented with the chief complaint of severe pain crises.

A number of studies suggest that women with sickling disorders are at risk of fetal growth restriction (FGR) due to vascular stasis in the uteroplacental unit ${ }^{8,21}$ as well as preeclampsia. Serial ultrasound imaging to detect FGR would facilitate timely intervention as a means of reducing perinatal morbidity and mortality rates for affected pregnancies. ${ }^{21}$ While pain crisis and preterm labor are more commonly seen in HbSS disease, they are also manifestations of HbSC disease during pregnancy. Fetal surveillance to evaluate the development of FGR ${ }^{22}$ is warranted because of the possible venous stasis in the uteroplacental unit due to HBSC associated increased viscosity. ${ }^{14}$

Generally, delivery can be accomplished vaginally with cesarean section reserved for obstetric indications. Spontaneous labor rather than labor induction is preferred as several investigators suggested that sickle cell crisis may be precipitated by labor induction. There is concern that prostaglandins may lead to RBC sickling, and, therefore, should be used with caution. All patients should be screened to ensure that they are receiving adequate nutrition. ${ }^{11}$ Folic acid supplement of $1 \mathrm{mg}$ daily is recommended for all women with sickling disorders due chronic hemolysis, with the increased associated risk for folate deficiency. In addition, prenatal supplements should include prenatal vitamins, Folic acid $5 \mathrm{mg}$ daily reduces the risk of neural tube defects (NTDs) and compensates for the increased demand for folate during pregnancy. ${ }^{21}$

Patients should be given counseling to avoid contact with infected individuals. Of particular concern for patients with sickle cell anemia is infection with parvovirus B19. This infection can cause an aplastic crisis,${ }^{14}$ in the gravidas affected by SCD resulting in life-threatening bone marrow suppression in the fetus. If infection does occur, close follow-up of maternal and fetal hematologic status is important.

Sickle cell pain crisis may cause a rise in the serum ferritin that may persist for 1-3 weeks. ${ }^{23}$ Phlebotomy may be useful to reducing blood viscosity by not only reducing intracellular hemoglobin concentration but also reducing the hematocrit level. It should be noted that in patients with symptomatic iron deficiency, iron therapy with careful monitoring may be considered with the understanding that even brief iron therapy may precipitate a sickle cell crisis. ${ }^{23}$

\section{Conclusion}

In conclusion, women with SCD have increased rates of maternal and fetal complications. These complications persist despite current medical management and are seen in milder genotypes such as HbSC. Our review suggests perinatal outcome is improved when pregnancies complicated by sickle cell disorders are managed by a multidisciplinary team that addresses the evolving requirements of the parturient and fetus. ${ }^{20}$

\section{Acknowledgments}

Special thanks to Ms. Judith Wilkinson, Medical Librarian, from Lincoln Medical and Mental Health Center Science Library for assistance in finding the reference articles.

\section{Conflicts of interest}

None.

\section{References}

1. Weatherhall DJ. The inherited diseases of hemoglobin are an emerging global health burden. Blood. 2010;115(22):4331-4336.

2. Bunn HF, Noguchi CT, Hofrichter J, et al. Molecular and cellular pathogenesis of hemoglobin SC disease. Proc Natl Acad Sci. 1982;79(23):7527-7531.

3. Parents guide, Hemoglobin SC Disease Brochure, Department of Health and Hospital, State of Louisiana.

4. Lichtin AE. Hemoglobin S-C disease. The Merck Manual. 2013.

5. Ballas SK, Lewis CN, Noone AM, et al. Clinical Hematological, and Biochemical Features of $\mathrm{Hb} \mathrm{SC}$ Disease. Am J Hematol. 1982;13(1):37-51

6. Nagel RL, Fabry ME, Steinberg MH. The paradox of hemoglobin SC disease. Blood Rev. 2003;17(3):167-178.

7. Lionnet F, Hammoudi N, Stankovic Stojanovic K, et al. Hemoglobin SC disease complications: a clinical study of 179 cases. Haematologica. 2012;97(8):P1136-P1141.

8. Schnog JB, Duits AJ, Muskiet FA, et al. Sickle cell disease, a general overview. Neth J Med. 2004;62(10):364-374.

9. Rosse WF, Narla M, Petz LD, et al. New Views of Sickle Cell Disease Pathophysiology and Treatment. Hematology Am Soc Hematol Educ Program. 2000;2-17. 
10. Markham MJ, Lottenberg R, Zumberg M. Role of phlebotomy in the management of hemoglobin SC disease: Case report and review of literature. Am J Hematol. 2003;73(2):121-125.

11. Rappaport VJ, Velazquez M, Williams K. Hemoglobinopathies in pregnancy. Obstet Gynecol Clin North Am. 2004;31(2):287-317.

12. Resende Cardoso PS, Lopes Pessoa de Aguiar RA, Viana MB. Clinical complications in pregnant women with sickle cell disease: prospective study of factors predicting maternal death or near miss. Rev Bras Hematol Hemoter. 2014;36(4):256-263.

13. Powars DR, Hiti A, Ramicone E, et al. Outcome in Hemoglobin SC Disease: A Four Decade Observational Study of Clinical, Hematologic, and Genetic Factors. Am J Hematol. 2002;70(3):206-215.

14. Milner PF, Kraus AP, Sebes JI, et al. Sickle Cell disease as a cause of osteonecrosis of the femoral head. $N$ Engl J Med. 1991;325(21):1476-1481

15. McCurdy PR, Sherman AS. Irreversibly sickled cells and red cell survival in sickle cell anemia: a study with both DF32P and 51CR. Am J Med. 1978;64(2):253-258.

16. McCurdy PR, Mahmood L, Sherman AS. Red cell life span in sickle cell-hemoglobin C disease with a note about sickle cell-hemoglobin $O$ $A R A B$. Blood. 1975;45(2):273-279.
17. Seoud MA, Cantwell C, Nobles G, et al. Outcome of pregnancies complicated by sickle cell and sickle-C hemoglobinopathies. $\mathrm{Am} \mathrm{J}$ Perinatol. 1994;11(3):187-191.

18. Sun PM, Wilbourn W, Raynor D, et al. Sickle cell disease in pregnancy: twenty years of experience at Grady Memorial Hospital, Atlanta, Georgia. Am J Obstet Gyencol. 2001;184(6):1127-1130.

19. Pantanowitz L, Schwartz R, Balogh K. Images in pathology. The placenta in sickle cell disease. Arch Pathol Lab Med. 2000;124(10):1565.

20. Oteng-Ntim E, Ayensah B, Knight M, et al. Pregnancy outcome in patients with sickle cell disease in the UK - a national cohort study comparing sickle cell anemia (HbSS) with HbSC disease. Br J Haematol. 2015;169(1):129-137.

21. Royal College of Obstetricians and Gynaecologists (RCOG). Management of sickle cell disease in pregnancy. London (UK): Royal College of Obstetricians and Gynaecologists (RCOG). Green-top guideline. 2011;no.61.p:1-20.

22. ACOG Committee on Obstetrics. ACOG Practice Bulletin No. 78: hemoglobinopathies in pregnancy. Obstet Gynecol. 2007;109(1):229-237.

23. Koduri PR. Iron in sickle cell disease: a review on why less is better. $A m$ J Hematol. 2003;73(1):59-63. 